\title{
Clusterin inhibition using OGX-0I I synergistically enhances antitumour activity of sorafenib in a human renal cell
} carcinoma model

\author{
Y Kususda', H Miyake*,', ME Gleave ${ }^{2}$ and M Fujisawa' \\ 'Division of Urology, Kobe University Graduate school of Medicine, 7-5-I Kusunoki-cho, Chuo-ku, Kobe 650-00 I7, Japan; ${ }^{2}$ Vancouver Prostate Centre, \\ Vancouver General Hospital, Vancouver, Canada
}

BACKGROUND: The objective of this study was to investigate whether the therapeutic activity of sorafenib could be enhanced by combining with OGX-OII, an antisense oligodeoxynucleotide (ODN) targeting clusterin, in renal cell carcinoma (RCC). METHODS: We investigated the effects of combined treatment with OGX-0II and sorafenib on a human RCC ACHN model both in vitro and in vivo.

RESULTS: Although clusterin expression was increased by sorafenib, additional treatment of ACHN with OGX-OII significantly blocked the upregulation of clusterin induced by sorafenib. Despite the lack of a significant effect on the growth of ACHN, OGX-O I I synergistically enhanced the sensitivity to sorafenib, reducing the $I_{50}$ by $>50 \%$. Apoptotic changes were intensively detected in ACHN after combined treatment with OGX-OII and a sublethal dose of sorafenib, but not either agent alone. Furthermore, this combined treatment resulted in the marked downregulation of phosphorylated Akt and p44/42 mitogen-activated protein kinase in $\mathrm{ACHN}$ compared with treatment with either agent alone. In vivo systemic administration of OGX-0I I plus sorafenib significantly decreased the ACHN tumour volume compared with control ODN plus sorafenib.

CONCLUSION: Combined use with OGX-OII may be useful in enhancing the cytotoxic effect of sorafenib on RCC by inducing apoptosis and inactivating major signal transduction pathways.

British Journal of Cancer (2012) 106, 1945-1952. doi:I0.1038/bjc.2012.209 www.bjcancer.com

Published online 15 May 2012

(C) 2012 Cancer Research UK

Keywords: renal cell carcinoma; sorafenib; clusterin; OGX-OI I

Renal cell carcinoma (RCC) is the most common malignancy of the adult kidney, and annual estimates of newly diagnosed cases have been steadily increasing. One of the most unique characteristics of RCC is the high incidence of metastatic spread; that is, it has been reported that $\sim 30 \%$ of patients with RCC demonstrate metastasis at diagnosis, and $20-40 \%$ of those with localised disease who are surgically treated with curative intent subsequently develop metastatic diseases (Rini et al, 2008). Because a phenotype of RCC is highly resistant to conventional cytotoxic chemotherapy, immunotherapy using cytokines has been applied to patients with metastatic RCC as first-line therapy. However, limited efficacy is achieved by this treatment with an objective response rate of $<20 \%$; therefore; metastatic RCC has generally resulted in a poor prognosis with a median overall survival of $\sim 1$ year (Parton et al, 2006; Miyake et al, 2009).

In recent years, novel molecular-targeted agents have been developed based on the precise understanding of molecular mechanisms underlying the progression of RCC, and the introduction of these new drugs has induced a dramatic paradigm shift in the therapeutic strategy for metastatic RCC (Bellmunt et al, 2007; Lane et al, 2007). Of these, sorafenib, an orally active multikinase

*Correspondence: Dr H Miyake; E-mail: hideakimiyake@hotmial.com Revised 17 April 2012; accepted 19 April 2012; published online 15 May 2012 inhibitor, is one of the most widely used molecular-targeted agents against metastatic RCC (Wilhelm et al, 2006). It has been shown to have inhibitory effects on tumour cell proliferation and angiogenesis in preclinical RCC models through the inactivation of Raf- 1 , vascular endothelial growth factor receptor-1, -2 and -3 , plateletderived growth factor- $\beta$, c-kit and FMS-like tyrosine kinase-3 (Wilhelm et al, 2008). In a clinical setting as well, the excellent antitumour activity of sorafenib against RCC was demonstrated, showing a significantly favourable progression-free survival compared with a placebo in a phase III randomised trial (Escudier et al, 2007). However, several limitations of the treatment of metastatic RCC using sorafenib have been pointed out, including the low proportion of patients achieving a complete response and the short interval of a durable response (Stadler et al, 2010). Considering these findings, it would be of interest to develop a novel therapeutic strategy to further enhance the efficacy of sorafenib by combining with a drug exerting an antitumour activity through a mechanism different from this agent.

Clusterin was first isolated from ram rete testes fluid, and it has important roles in various pathophysiological processes, including tissue remodelling, reproduction, lipid transport, complement regulation and apoptosis (Shannan et al, 2006). As clusterin expression is markedly increased in various benign and malignant tissues undergoing apoptosis, it has been regarded as a marker of cell death. Recent studies, however, have provided conflicting evidence showing the powerful antiapoptotic activity of clusterin 
in various kinds of preclinical cancer model (Miyake et al, 2000b, c; Miyake et al, 2001a, 2004; Zellweger et al, 2002). The interaction of clusterin with signal transduction pathways associated with cell proliferative and antiapoptotic events, such as the suppression of p53-activating stress signals, stabilisation of cytosolic Ku70-Bax protein complex, enhancement of Akt phosphorylation and increase in NF- $\kappa$ B nuclear transactivation, have been shown to be involved in mechanisms by which clusterin exerts antiapoptotic functions (Zoubeidi et al, 2010a). In human RCC models as well, we identified clusterin as an antiapoptotic gene upregulated by proapoptotic stimuli that confers therapeutic resistance (Hara et al, 2001; Miyake et al, 2001b; Zellweger et al, 2001). Furthermore, our recent studies also showed that the overexpression of clusterin is closely associated with disease progression as well as the prognosis in patients with RCC who underwent radical nephrectomy (Miyake et al, 2002; Kurahashi et al, 2005). Collectively, these findings suggest that if upregulated following treatment with molecular-targeted agents, clusterin could be an attractive therapeutic target for patients with advanced RCC who are treated with such agents, including sorafenib.

OGX-011 is a second-generation phosphorothioate antisense oligodeoxynucleotide (ODN) currently in late-stage clinical development that significantly downregulates clusterin expression and enhances the efficacy of anticancer therapies in various human malignant tumours, including RCC (Chi et al, 2010; Zoubeidi et al, 2010a). In this study, therefore, we investigated whether knockdown of clusterin using OGX-011 potentiates the therapeutic effect of sorafenib in a human RCC ACHN model.

\section{MATERIALS AND METHODS}

\section{Tumour cell line}

Human RCC cell lines, ACHN, Caki-1 and 786-O, were purchased from the American Type Culture Collection (Rockville, MD, USA) and were used within 6 months of resuscitation. Cells were maintained in MEM (Life Technologies Inc., Gaithersburg, MD, USA) supplemented with $5 \%$ heat-inactivated fetal bovine serum.

\section{Therapeutic agents}

Sorafenib was purchased from Toronto Research Chemicals Inc. (Toronto, Canada). A stock solution of sorafenib was prepared with dimethyl sulfoxide, and diluted with $\mathrm{PBC}$ to the required concentrations before each experiment.

\section{Oligodeoxynucleotide}

OGX-011 is a second-generation 21-mer ODN with a $2^{\prime}-O-$ (2-methoxy)ethyl modification, generously provided by OncoGenex Technologies Inc. (Vancouver, Canada). The sequence of the OGX-011, targeting the human clusterin gene corresponding to the translation initiation site was 5'-CAGCAGCAGAGTCTTCATC AT- $3^{\prime}$. The sequence of ODN used as a control in this study was $5^{\prime}$-CAGCAG-CAGAGTATTTATCAT-3'. Both ODNs displayed a length purity of $>95 \%$ with a phosphodiester content of $<0.3 \%$. A Basic Local Alignment Search Tool search of the National Center for Biotechnology Information database showed no homology of OGX-011 and control ODN to any other known human genes.

\section{Treatment cells with ODN}

Cells were treated with various concentrations of ODN after preincubation for $20 \mathrm{~min}$ with $3 \mathrm{mg} \mathrm{ml}^{-1}$ oligofectamine (Invitrogen Corporation, Carlsbad, CA, USA) in serum-free OPITMEM (Invitrogen Corporation). Four hours after the beginning of incubation, the medium was replaced with the standard culture medium described above. Cells were treated once daily for
2 successive days and then harvested $48 \mathrm{~h}$ after final treatment for protein isolation.

\section{Cell proliferation assay}

The in vitro growth inhibitory effects of OGX-011 and/or sorafenib on ACHN, Caki-1 and 786-O cells were assessed using Cell Counting Kit-8 (Dojindo Molecular Technologies, Kumamoto, Japan). Briefly, $5 \times 10^{4}$ cells were seeded in each well of 12 -well plates and allowed to attach overnight, and treated once daily with control ODN or OGX-011 for $48 \mathrm{~h}$. Following ODN treatment, cells were treated with various concentrations of sorafenib. After $48 \mathrm{~h}$ of incubation, the number of cells was counted. Each assay was performed in triplicate.

\section{Clonogenic assay}

Following the treatment with ODN as described above, cells were cultured in either standard medium or that containing $5 \mu \mathrm{m}$ sorafenib for $24 \mathrm{~h}$. Cells were then trypsinised, resuspended in standard medium, and cell concentrations were determined. Known numbers of cells were plated into Petri dishes containing standard medium, and colonies $>50$ cells were counted after 10 days of growth. Plating efficiency was defined as number of colonies divided by the number of plated cells. Each assay was performed in triplicate.

\section{Detection of apoptosis in cultured cells}

Cells undergoing apoptosis were identified using In Situ Cell Death Detection Kit POD (Roche Applied Science, Indianapolis, IN, USA). Briefly, $5 \times 10^{4}$ cells were seeded in $10-\mathrm{cm}$ dishes, and were treated with ODN as described above. Following ODN treatment, cells were cultured in either standard medium or that containing $5 \mu \mathrm{m}$ sorafenib for $24 \mathrm{~h}$. Cells were then fixed in paraformaldehyde for $60 \mathrm{~min}$, incubated in permeabilisation solution for $2 \mathrm{~min}$ and TUNEL reaction mixture for $60 \mathrm{~min}$, and analysed using fluorescence microscopy.

Quantitative analysis of apoptotic cells following treatment with ODN and sorafenib was performed using In Situ Cell Death Detection Kit ELISA (Roche Applied Science) according to the manufacturer's instructions. Each assay was performed in triplicate.

\section{Western blot analysis}

Samples containing equal amounts of protein $(20 \mu \mathrm{g})$ from lysates of the cultured cells treated with ODN and/or sorafenib according to the schedule described above were subjected to SDSpolyacrylamide gel electrophoresis and transferred to a nitrocellulose filter. The filter was blocked in PBS containing 5\% nonfat milk powder at $4{ }^{\circ} \mathrm{C}$ overnight and then incubated for $1 \mathrm{~h}$ with antibodies against clusterin, PARP, Bcl-2, Bax, Bcl-xL, Mcl-1 (Santa Cruz Biotechnology, Santa Cruz, CA, USA), p53 (Epitomics, Burlingame, CA, USA), total and phosphorylated Akt, p44/42 mitogen-activated protein kinase (MAPK), signal transducers and activation of transcription 3 (STAT3; Cell Signaling Technology, Danvers, MA, USA) and $\beta$-actin (Santa Cruz Biotechnology). The filters were then incubated for $30 \mathrm{~min}$ with horseradish peroxideconjugated secondary antibodies (Santa Cruz Biotechnology), and specific proteins were detected using an enhanced chemiluminescence Western Blot analysis system (Amersham, Life Science, Arlington Heights, IL, USA). The strength of each signal density was determined using a densitometer (Bio-Tek Instruments, Inc., Winooski, VT, USA).

\section{Assessment of in vivo tumour growth}

Male athymic nude mice (BALB/c-nu/nu males, 5- to 6-week-old) were purchased from Clea Japan (Tokyo, Japan) and housed in a 
controlled environment at $22{ }^{\circ} \mathrm{C}$ on a 12 -h light, 12-h dark cycle. Animal experiments were conducted in accordance with the National Institutes of Health Guide for the Care and Use of Laboratory Animals. Approximately $5 \times 10^{5}$ of ACHN cells were injected subcutaneously with $100 \mu \mathrm{l}$ of Matrigel (Becton Dickinson, Franklin Lakes, NJ, USA) into the left flank of mice. Two weeks after the implantation of tumour cells, mice were randomly selected for treatment with control ODN alone, control ODN plus sorafenib, OGX-011 alone or OGX-011 plus sorafenib. Each experimental group consisted of eight mice. After randomisation, $12.5 \mathrm{mg} \mathrm{kg}^{-1}$ of control ODN or OGX-011 was injected intraperitoneally once daily for the first week, and three times per week thereafter. From day 7, either sorafenib at a dose of $20 \mathrm{mg} \mathrm{kg}^{-1}$ or vehicle was administered orally twice a week. Subcutaneous tumour growth was measured at least once per week using calipers and calculated using the formula: length $\times$ width $\times$ depth $\times 0.5236$.

\section{Histopathological study of in vivo tumour}

In vivo subcutaneous tumours were harvested from nude mice undergoing treatment with control ODN alone, control ODN plus sorafenib, OGX-011 alone or OGX-011 plus sorafenib for 8 weeks according to the schedule shown above. Immunohistochemical staining of tumour specimens was performed as described previously (Behnsawy et al, 2011). Briefly, sections from formaldehyde-fixed, paraffin-embedded tissue were deparaffinised with xylene and rehydrated. After the blocking of endogenous peroxidase with $3 \%$ hydrogen peroxidase in methanol, sections were stained with antibodies against clusterin and Ki-67 (Santa Cruz Biotechnology) for $60 \mathrm{~min}$. Sections were subsequently incubated with biotinylated secondary IgG (Vector Laboratories, Burlingame, CA, USA) for $30 \mathrm{~min}$. After incubation in avidinbiotin peroxidase complex for $30 \mathrm{~min}$, samples were exposed to diaminobenzidine tetrahydrochloride solution and counterstained using methyl green. In addition, TUNEL staining of subcutaneous tumours was performed using In Situ Cell Death Detection Kit POD as described above.

\section{Statistical analysis}

Differences between the two groups were compared using the unpaired $t$-test. All statistical calculations were performed using Statview 5.0 software (Abacus Concepts, Inc., Berkley, CA, USA), and $P$-values $<0.05$ were considered significant.

\section{RESULTS}

\section{Inhibition of clusterin expression in ACHN cells by OGX-011}

Western blot analysis was used to evaluate the effects of control ODN and OGX-011 on the expression levels of clusterin protein in ACHN cells. As shown in Figure 1A, treatment of ACHN cells with OGX-011 reduced the expression levels of clusterin protein in a dose-dependent manner. However, clusterin expression was not affected by treatment with control ODN, suggesting the sequence specificity of the effect of OGX-011 on the clusterin expression in ACHN cells.

\section{Sorafenib-induced clusterin expression and its inhibition by OGX-011 in ACHN cells}

ACHN cells were treated with various concentrations of sorafenib, and changes in expression levels of clusterin protein were assessed by western blot analysis. Sorafenib treatment resulted in the dosedependent induction of clusterin protein in ACHN cells (Figure 1B). We then evaluated the effect of pretreatment with OGX-011 on the subsequent upregulated expression of clusterin
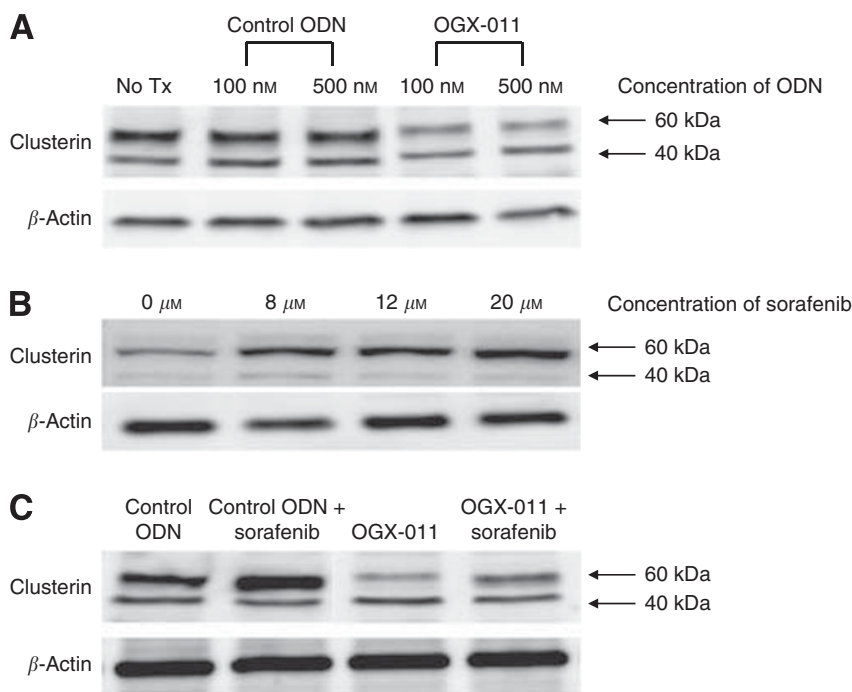

Figure I Effects of $O G X-0 I \mid$ and/or sorafenib treatment on clusterin expression in ACHN cells. (A) ACHN cells were treated daily with control ODN or $\bigcirc \mathrm{GX}-\mathrm{OI}$ I for 2 days, and then incubated in the standard medium for $48 \mathrm{~h}$. Protein was then extracted from cultured cells, and analysed for clusterin and $\beta$-actin levels by western blotting. No $\mathrm{T} \times$, untreated cells. (B) ACHN cells were treated with various doses of sorafenib for $48 \mathrm{~h}$. Protein was then extracted from cultured cells, and analysed for clusterin and $\beta$-actin levels by western blotting. (C) ACHN cells were treated daily with control ODN or 500 nM OGX-0 I I for 2 days. Following incubation in either standard medium or that containing $5 \mu \mathrm{M}$ sorafenib for $48 \mathrm{~h}$, protein was extracted from cultured cells, and analysed for clusterin and $\beta$-actin levels by western blotting.

protein induced by sorafenib. As shown in Figure 1C, pretreatment of ACHN cells with OGX-011 significantly inhibited the induction of clusterin by sorafenib.

\section{Enhanced sensitivity of ACHN cells to sorafenib by combined treatment with OGX-011}

To determine whether treatment with OGX-011 enhances the cytotoxic effect of sorafenib, ACHN cells were treated with either control ODN or OGX-011 and then incubated with medium containing various concentrations of sorafenib. As shown in Figure 2A, pretreatment with OGX-011, but not that with control ODN, synergistically enhanced the sensitivity of ACHN cells to sorafenib in a dose-dependent manner, reducing the $\mathrm{IC}_{50}$ of sorafenib by $>50 \%$. In addition, similar synergistic effect on ACHN cells was observed in clonogenic assay following combined treatment with OGX-011 and a sublethal dose of sorafenib (Figure 2B).

To confirm whether the cytotoxic effect of sorafenib is enhanced by treatment with OGX-011 in other human RCC cell lines, Caki-1 and 786-O were treated with sorafenib in addition to either control ODN or OGX-011 according to the same schedule described above. As observed in ACHN cells, pretreatment with OGX-011 resulted in the synergistically enhanced sensitivities of sorafenib in both Caki1 and 786-O cells compared with that with control ODN; that is, the $\mathrm{IC}_{50}$ of sorafenib in Caki-1 and 786-O cells decreased by $>50 \%$ and $>70 \%$, respectively, following treatment with OGX-011 (data not shown).

Apoptotic features of cultured ACHN cells following combined treatment with OGX-011 and a sublethal dose of sorafenib were then evaluated using a modified TUNEL technique. Apoptotic cell death was barely detected in ACHN cells after treatment with control ODN alone, control ODN plus sorafenib, or OGX-011 alone; however, there was a significant proportion of ACHN cells undergoing apoptosis after combined treatment with OGX-011 and 

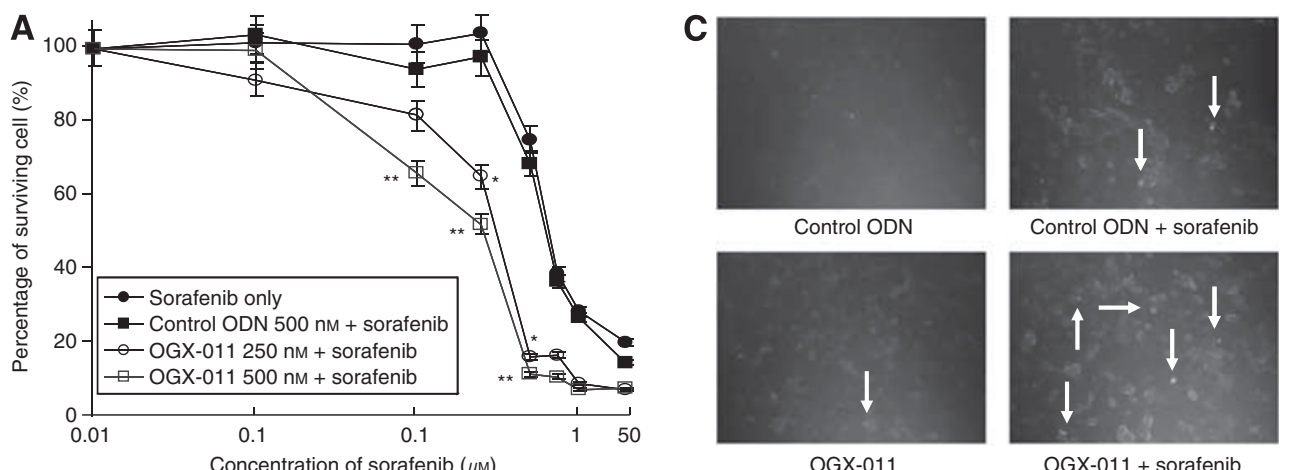

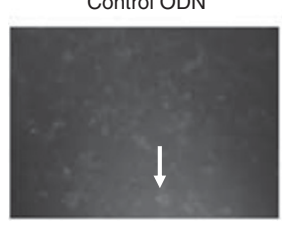

OGX-011

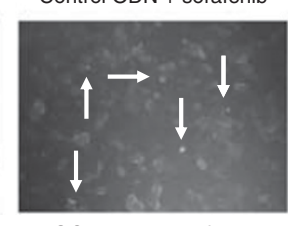

OGX-011 + sorafenib

D

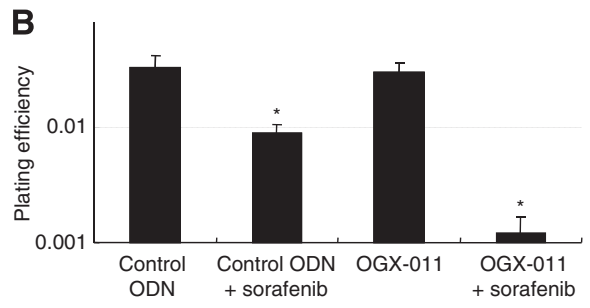

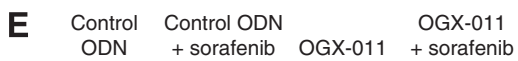

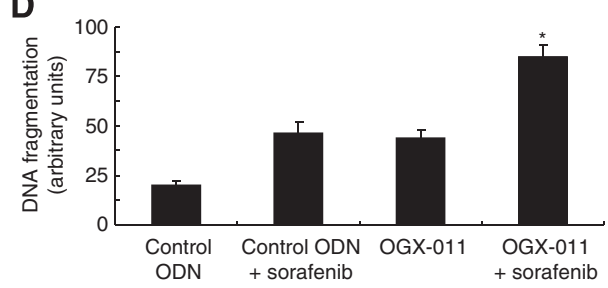

$\longleftarrow 116 \mathrm{kDa}$ (uncleaved intact form)

$\longleftarrow 85 \mathrm{kDa}$ (cleaved form)

Figure 2 Effect of combined treatment with OGX-0II and sorafenib on ACHN cell growth and apoptosis. (A) ACHN cells were treated with 500 nM control ODN, 250 or $500 \mathrm{~nm}$ OGX-II once daily for 2 days. Following ODN treatment, the medium was replaced with that containing various doses of sofarenib. After $48 \mathrm{~h}$ of incubation, the number of viable cells was determined by a cell proliferation assay. Each data point represents the mean of triplicate analyses; bars, s.d.; ** and * differ from controls $(P<0.0$ I and $P<0.05$, respectively) by unpaired $t$-test. (B) Following treatment with $500 \mathrm{nM}$ control $O D N$ or OGX-I I once daily for 2 days, ACHN cells were incubated in either standard medium or that containing $5 \mu \mathrm{M}$ sorafenib for $24 \mathrm{~h}$. ACHN cells were then trypsinised and resuspended in standard medium. Colonies $>50$ cells were counted after 10 days of growth, and plating efficiencies (number of colonies/ number of plated cells) were calculated. Columns, mean of three independent experiments; bars, s.d.; *, differs from controls $(P<0.0 \mathrm{I})$ by unpaired $t$-test. (C) After the same treatment schedule as described above, cells undergoing apoptosis were detected by a modified TUNEL technique. Arrows, positively stained cells. (D) After the same treatment schedule as described above, the quantitative degree of apoptosis was measured by an In Situ Cell Death Detection ELISA kit that can detect cytoplasmic histone-associated DNA fragments. Columns, mean of three independent experiments; bars, s.d.; * differs from controls $(P<0.05)$ by unpaired $t$-test. $(\mathbf{E})$ Proteins were extracted from ACHN cells after the same treatment as described above, and analysed by western blotting with an anti-PARP antibody.

sorafenib (Figure 2C). A quantitative measurement of apoptotic cells using an ELISA assay, that can detect cytoplasmic histoneassociated DNA fragments, showed findings equivalent to those in the modified TUNEL assay (Figure 2D); that is, the quantitative degree of apoptosis after combined treatment with OGX-011 and sorafenib was approximately twice as much as that after either agent alone. To further confirm the effect of this combined treatment on apoptosis induction, western analysis of PARP protein was carried out. As shown in Figure 2E, evident cleavage of PARP protein was detected only after combined treatment with sorafenib and OGX-011.

\section{Expression patterns of key molecules involved in apoptosis and signal transduction in ACHN cells after combined treatment with OGX-011 and sorafenib}

Western blot analyses were used to determine whether the expression patterns of several molecules involved in apoptosis are modulated in ACHN cells after combined treatment with OGX011 and sorafenib. As shown in Figure 3A, the expression of Bax protein after combined treatment with OGX-011 and sorafenib was similar to that after treatment with either agent alone. However, the expression levels of Bcl-2, Bcl-xL and p53 after the combined treatment were significantly upregulated compared with those after treatment with either agent alone. In addition, Mcl-1 protein expression was markedly inhibited by treatment with sorafenib either alone or in combination with OGX-011.
Similarly, changes in expression levels of molecules involved in major signal transduction pathways in ACHN cells after combined treatment with OGX-011 and sorafenib were investigated. There were no significant effects of the combined treatment on the expression levels of both total and phosphorylated STAT3 compared with that of treatment with either agent alone. However, the combined treatment resulted in the significant inhibition of total Akt and p44/42 MAPK compared with treatment with either agent alone. Furthermore, despite the marked inhibition of both phosphorylated Akt and p44/42 MAPK after treatment with sorafenib alone, the combined treatment almost completely inactivated both Akt and p44/42 MAPK pathways without detectable proteins corresponding to phosphorylated Akt and p44/42 MAPK (Figure 3B).

\section{Therapeutic efficacy of combined treatment with OGX-011} and sorafenib on ACHN tumours in vivo

Male athymic nude mice bearing subcutaneous ACHN tumours were randomly selected for treatment with control ODN alone, control ODN plus sorafenib, OGX-011 alone or OGX-011 plus sorafenib. The mean tumour volume was similar at the beginning of treatment in each of these four treatment groups. As shown in Figure 4, despite the lack of a significant difference in the growth inhibitory effect on ACHN tumours between OGX-011 and control ODN without sorafenib, combined treatment with OGX-011 and sorafenib resulted in the synergistic inhibition of the growth of 
A

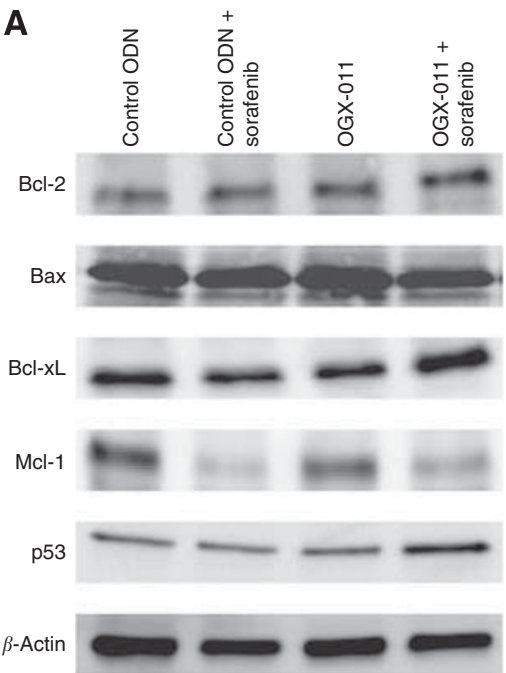

B

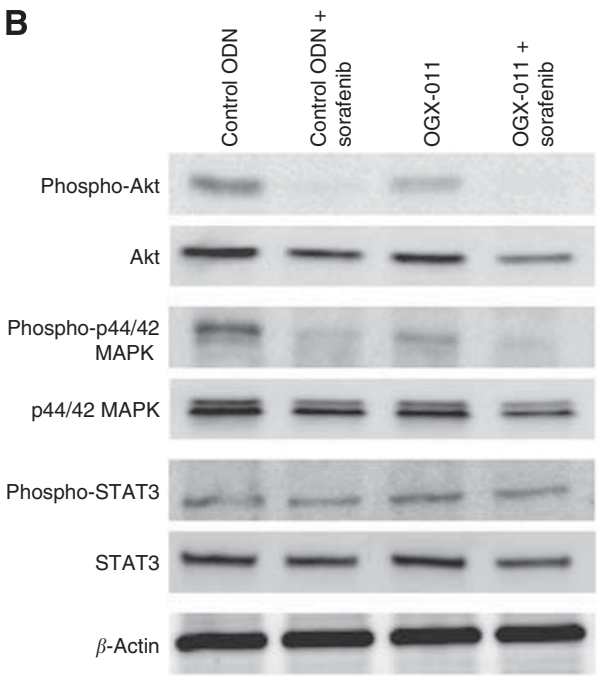

Figure 3 Changes in expression patterns of key molecules involved in apoptosis and signal transduction in ACHN cells after combined treatment with OGX-OII and sorafenib. (A) ACHN cells were treated with $500 \mathrm{nM}$ control ODN or OGX-II once daily for 2 days, and then incubated in either standard medium or that containing $5 \mu \mathrm{M}$ sorafenib for $24 \mathrm{~h}$. Protein was then extracted from cultured cells, and analysed for Bcl-2, Bax, Bcl-xL, Mcl- I, p53 and $\beta$-actin levels by western blotting. (B) After the same treatment schedule as described above, protein was extracted from cultured cells, and analysed for total and phosphorylated (phospho) Akt, p44/42 MAPK, STAT3 and $\beta$-actin levels by western blotting.

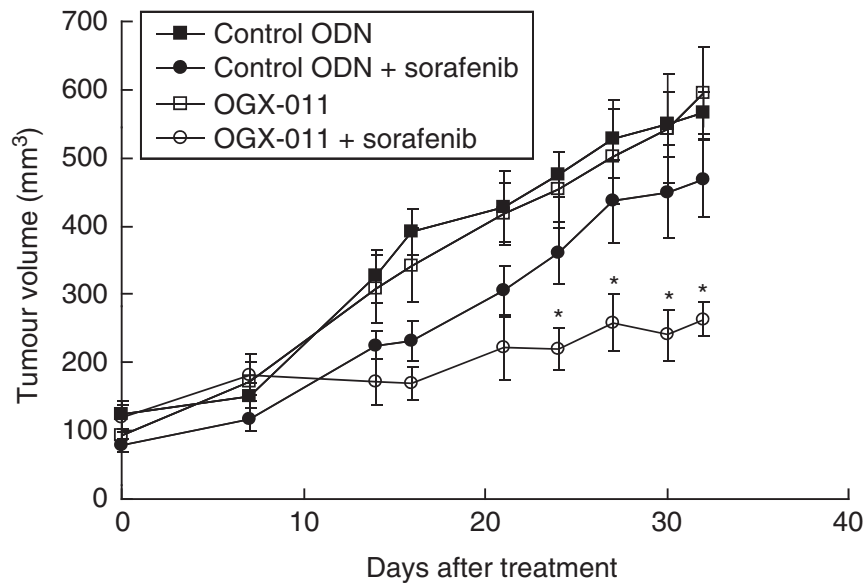

Figure 4 Effect of combined treatment with $\mathrm{OGX}-\mathrm{OI} I$ and sorafenib on ACHN tumour growth. Nude mice bearing ACHN tumours were randomly selected for treatment with control ODN alone, control ODN plus sorafenib, OGX-OII alone or OGX-0I I plus sorafenib. After randomisation, $12.5 \mathrm{mg} \mathrm{kg}^{-1}$ control ODN or OGX-0II was injected intraperitoneally once daily for the first week, and three times per week thereafter. From day 7 , either sorafenib at a dose of $20 \mathrm{mg} \mathrm{kg}^{-1}$ or vehicle was administered orally twice a week. The subcutaneous tumour growth was measured at least once per week using calipers and calculated by the formula: length $\times$ width $\times$ depth $\times 0.5236$. Each data point represents the mean tumour volume in each experimental group containing eight mice; bars, s.d.; *, differs from controls $(P<0.05)$ by unpaired $t$-test.

ACHN tumours compared with combined treatment with control ODN and sorafenib. In addition, no obvious side effects were observed in any of the treatment groups.

We then compared the changes in clusterin expression and cell proliferative and apoptotic features in ACHN tumours among treatment groups. As observed in the in vitro study, clusterin expression in ACHN tumours was induced by the administration of sorafenib, whereas OGX-011 effectively inhibited the expression of clusterin in ACHN tumours. Furthermore, despite the lack of differences in the proportions of cells positive for Ki-67 immunostaining and the TUNEL assay between the groups treated with OGX-011 and that with control ODN, the inhibition of cell proliferation and induction of apoptosis in ACHN tumours treated with OGX-011 and sorafenib were more remarkable than those in ACHN tumours treated with control ODN and sorafenib (Figure 5).

\section{DISCUSSION}

The recent introduction of molecular-targeted agents into clinical practice has revolutionised the therapeutic strategy against advanced RCC. Although molecular-targeted agents have definitively improved the prognosis of patients with advanced RCC, disease progression eventually occurs during treatment with these agents (Bellmunt et al, 2007; Escudier et al, 2007; Lane et al, 2007). Accordingly, it would be of interest to simultaneously use a drug targeting molecular events involved in the acquisition of resistance to these agents in order to prolong the interval of durable response to these agents and subsequently achieve a more favourable prognosis in patients with advanced RCC.

Recent studies have characterised several molecules that are upregulated in the adaptive response to a wide variety of proapoptotic stimuli and function to inhibit treatment-induced apoptotic cell death (Miyake et al, 2000d; Kiyama et al, 2003; Rocchi et al, 2005; Yamanaka et al, 2005; So et al, 2007). Of these, clusterin, a stress-activated cytoprotective chaperone, has become an attractive target in cancer therapy because of its multifunctional roles in signalling and transcriptional networks underlying the progression as well as resistance to anticancer therapy in several types of malignant tumour, including RCC (Miyake et al, 2000b, c, 2001a, b, 2002, 2004; Hara et al, 2001; Zellweger et al, 2001, 2002; Kurahashi et al, 2005; Chou et al, 2009; Zhong et al, 2010). For example, the enhanced sensitivity of human RCC caki-2 cells to a chemotherapeutic agent by the inhibition of clusterin expression was reported (Zellweger et al, 2001). Considering these findings, we investigated whether the therapeutic efficacy of sorafenib, one of the most widely used molecular-targeted agents against RCC through the inactivation of multiple tyrosine kinases, could be enhanced by combining antisense ODN targeting the clusterin gene, OGX-011, in a human RCC ACHN model.

OGX-011, a second-generation antisense inhibitor targeting the translation initiation site of the human clusterin gene, has been 


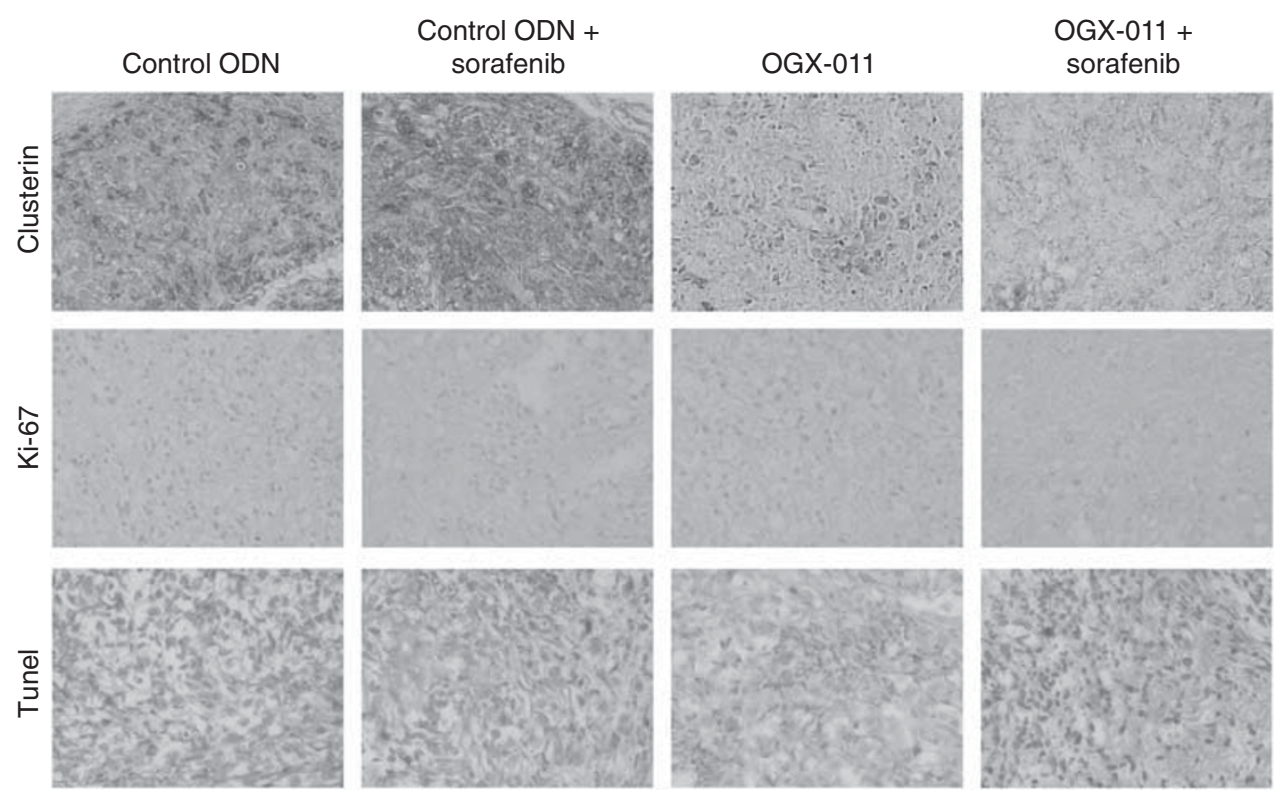

Figure 5 Histopathological study of ACHN tumours after combined treatment with $O G X-0 I I$ and sorafenib. In vivo subcutaneous tumours were harvested from nude mice undergoing treatment with control ODN alone, control ODN plus sorafenib, OGX-0 I I alone or OGX-0 I I plus sorafenib for 8 weeks according to the schedule shown in Figure 4. Sections from each tumour tissue were examined by immunohistochemical staining with antibodies against clusterin and Ki-67, and TUNEL staining.

shown to potently suppress the expression levels of clusterin both in vitro and in vivo (Miyake et al, 2000b, c, 2001a, 2004; Zellweger et al, 2002). Also in this study, we initially demonstrated the dosedependent inhibition of clusterin expression in ACHN cells on treatment with OGX-011. Furthermore, OGX-011 could markedly suppress clusterin expression even after sorafenib treatment, which resulted in an adopted induction of clusterin in $\mathrm{ACHN}$ cells. Treatment of ACHN cells with OGX-011 reduced the $\mathrm{IC}_{50}$ of sorafenib by $>50 \%$ and synergistically enhanced sorafenibinduced apoptosis, although no growth inhibitory effect was observed in ACHN cells treated with OGX-011 alone. These findings suggest that clusterin expression in RCC cells may confer a phenotype resistant to apoptosis induced by sorafenib; therefore, despite there being no significant effect on cell proliferation in the absence of other proapoptotic stimuli or cell death signals, the reduction in clusterin expression by OGX-011 may enhance the sensitivity of sorafenib to advanced RCC.

To date, several molecular mechanisms mediating enhanced cytotoxic effects of a wide variety of therapeutic stimuli by inhibiting clusterin expression have been reported (Zhang et al, 2005; Ammar and Closset, 2008; Chou et al, 2009; Zoubeidi et al, 2010b; Lamoureux et al, 2011). For example, elevated levels of clusterin were shown to promote prostate cancer cell survival by facilitating the degradation of COMMD1 and I- $\kappa \mathrm{B}$, thereby activating the canonical NF- $\kappa \mathrm{B}$ pathway (Zoubeidi et al, 2010b), while the elevated level of clusterin in human cancers was demonstrated to promote oncogenic transformation and tumour progression by interfering with Bax proapoptotic activities (Zhang et al, 2005). It is also of interest to explore the mechanism involved in the enhanced sensitivity to sorafenib of ACHN cells by combined treatment with OGX-011. In this study, expression levels of both $\mathrm{Bcl}-2$ and $\mathrm{Bcl}-\mathrm{xL}$ proteins in $\mathrm{ACHN}$ cells were significantly upregulated by combined treatment with a sublethal dose of sorafenib and OGX-011. Although not fully elucidated, these mechanisms may represent an adaptive change mediating cell survival through a stress-induced increase in several antiapoptotic genes, which function like small heat shock proteins to chaperone and stabilise conformations of proteins at times of cell stress (Miyake et al, 1999, 2000a; Zoubeidi et al, 2010a).
Consistent with previous studies (Augustine et al, 2010; Huber et al, 2011), however, another antiapoptotic protein, Mcl-1, was significantly downregulated by sorafenib either alone or in combination with OGX-011. Furthermore, an almost complete inactivation of Akt and p44/42 MAPK, signal transduction pathways with a potential impact on the proliferation of cancer cells, was observed in ACHN cells after combined treatment with OGX-011 and sorafenib. Recently, we reported a finding similar to that in the present study; that is, reduced cell viability by combined treatment with OGX-011 and HSP90 inhibitor resulted from a decreased phophorylated Akt level in human prostate cancer cells (Lamoureux et al, 2011). Collectively, these findings suggest that the enhanced antitumour activity of sorafenib in ACHN cells by combining with OGX-011 could be explained by, at least in part, the direct inhibition of their proliferation through the inactivation of major signalling pathways in addition to the modulation of apoptosis-related proteins.

Another point of interest is the in vivo effect of combined therapy with OGX-011 and sorafenib on ACHN tumours. In addition to a number of our previous studies demonstrating the excellent function of OGX-011 for inhibiting clusterin expression in vivo (Zoubeidi et al, 2010a; Lamoureux et al, 2011), phase II clinical studies reported more than $90 \%$ inhibition of clusterin in human prostate cancer tissues (Chi et al, 2005) and prolonged survival of 7 months when OGX-011 was combined with docetaxel in men with castration-resistant prostate cancer (Chi et al, 2008, 2010). In this study as well, OGX-011, which markedly reduced the expression level of clusterin protein in subcutaneously implanted ACHN tumours in nude mice, showed a synergistically inhibitory effect on the growth of ACHN tumours by combining sorafenib compared with control ODN combined with sorafenib. In addition to sorafenib, OGX-011 was also shown to exert an antiangiogenic activity in vivo (Jackson et al, 2005); therefore, this favourable growth inhibitory effect of combined OGX-011 and sorafenib therapy on in vivo ACHN tumours could partially be explained by the efficacious inhibition of angiogenesis by these two agents. Moreover, considering the data showing that the activity of sorafenib following daily administration at $400 \mathrm{mg}$ b.i.d. in human corresponded to that at $10-30 \mathrm{mg} \mathrm{kg}^{-1}$ in mouse 
(Wilhelm et al, 2008), the achievement of synergistic antitumour effect of this combined regimen could be expected in clinical setting as well. In this study, however, the combined regimen failed to completely eradicate subcutaneous ACHN tumours; therefore, it would be necessary to achieve a more pronounced therapeutic efficacy by further combining an agent with antitumour activity different from either OGX-011 or sorafenib, as, in our recent study, subcutaneously implanted human bladder KoTCC-1 tumours disappeared after treatment combining three different types of anticancer agents, including OGX-011, cisplatin and adenoviralmediated p53 gene transfer (Miyake et al, 2005). Moreover, it would also be important to try to identify useful biomarkers to predict the effect of combined OGX-011 and sorafenib therapy considering the introduction of this regimen into clinical practice.

In conclusion, the findings described in this study suggest that the expression of clusterin helps mediate the acquisition of a phenotype resistant to proapoptotic therapeutic stimuli, including a multiple tyrosine kinase inhibitor, sorafenib, in RCC. Moreover, we showed for the first time that clusterin inhibition using OGX-011 could synergistically enhance the antitumour activity of sorafenib against RCC. Accordingly, the preclinical data presented here provide principle support for designing clinical studies employing OGX-011 in combination with sorafenib for patients with advanced RCC.

\section{REFERENCES}

Ammar H, Closset JL (2008) Clusterin activates survival through the phosphatidylinositol 3-kinase/Akt pathway. J Biol Chem 283: 12851-12861

Augustine CK, Toshimitsu H, Jung SH, Zipfel PA, Yoo JS, Yoshimoto Y, Selim MA, Burchette J, Beasley GM, McMahon N, Padussis J, Pruitt SK, Ali-Osman F, Tyler DS (2010) Sorafenib, a multikinase inhibitor, enhances the response of melanoma to regional chemotherapy. Mol Cancer Ther 9: 2090-2101

Behnsawy HM, Miyake H, Abdalla MA, Sayed MA, Ael-F Ahmed, Fujisawa M (2011) Expression of cell cycle-associated proteins in nonmuscle-invasive bladder cancer: Correlation with intravesical recurrence following transurethral resection. Urol Oncol 29: 495-501

Bellmunt J, Montagut C, Albiol S, Carles J, Maroto P, Orsola A (2007) Present strategies in the treatment of metastatic renal cell carcinoma: an update on molecular targeting agents. BJU Int 99: 274-280

Chi KN, Eisenhauer E, Fazli L, Jones EC, Goldenberg SL, Powers J, Tu D, Gleave ME (2005) A phase I pharmacokinetic and pharmacodynamic study of OGX-011, a 20-methoxyethyl antisense oligonucleotide to clusterin, in patients with localized prostate cancer. J Natl Cancer Inst 97: 1287-1296

Chi KN, Hotte SJ, Yu EY, Tu D, Eigl BJ, Tannock I, Saad F, North S, Powers J, Gleave ME, Eisenhauer EA (2010) Randomized phase II study of docetaxel and prednisone with or without OGX-011 in patients with metastatic castration-resistant prostate cancer. J Clin Oncol 28: 4247-4254

Chi KN, Siu LL, Hirte H, Hotte SJ, Knox J, Kollmansberger C, Gleave M, Guns E, Powers J, Walsh W, Tu D, Eisenhauer E (2008) A phase I study of OGX-011, a 20-methoxyethyl phosphorothioate antisense to clusterin, in combination with docetaxel in patients with advanced cancer. Clin Cancer Res 14: 833-839

Chou TY, Chen WC, Lee AC, Hung SM, Shih NY, Chen MY (2009) Clusterin silencing in human lung adenocarcinoma cells induces a mesenchymalto-epithelial transition through modulating the ERK/Slug pathway. Cell Signal 21: 704-711

Escudier B, Eisen T, Stadler WM, Szczylik C, Oudard S, Siebels M, Negrier S, Chevreau C, Solska E, Desai AA, Rolland F, Demkow T, Hutson TE, Gore M, Freeman S, Schwartz B, Shan M, Simantov R, Bukowski RM (2007) Sorafenib in advanced clear-cell renal-cell carcinoma. N Engl J Med 356: 125-134

Hara I, Miyake H, Gleave ME, Kamidono S (2001) Introduction of clusterin gene into human renal cell carcinoma cells enhances their resistance to cytotoxic chemotherapy through inhibition of apoptosis both in vitro and in vivo. Ipn I Cancer Res 92: 1220-1224

Huber S, Oelsner $M$, Decker T, zum Büschenfelde CM, Wagner $M$, Lutzny G, Kuhnt T, Schmidt B, Oostendorp RA, Peschel C, Ringshausen I (2011) Sorafenib induces cell death in chronic lymphocytic leukemia by translational downregulation of Mcl-1. Leukemia 25: 838-847

Jackson JK, Gleave ME, Gleave J, Burt HM (2005) The inhibition of angiogenesis by antisense oligonucleotides to clusterin. Angiogenesis 8: 229-238

Kiyama S, Morrison K, Zellweger T, Akbari M, Cox M, Yu D, Miyake H, Gleave ME (2003) Castration-induced increases in insulin-like growth factor-binding protein 2 promotes proliferation of androgen-independent human prostate LNCaP tumors. Cancer Res 63: 3575-3584

Kurahashi T, Muramaki M, Yamanaka K, Hara I, Miyake H (2005) Expression of the secreted form of clusterin protein in renal cell carcinoma as a predictor of disease extension. BJU Int 96: 895-899

Lamoureux F, Thomas C, Yin MJ, Kuruma H, Beraldi E, Fazli L, Zoubeidi A, Gleave ME (2011) Clusterin inhibition using OGX-011 synergistically enhances Hsp90 inhibitor activity by suppressing the heat shock response in castrate-resistant prostate cancer. Cancer Res 71: 5838-5849

Lane BR, Rini BI, Novick AC, Campbell SC (2007) Targeted molecular therapy for renal cell carcinoma. Urology 69: 3-10

Miyake H, Hara I, Gleave ME, Eto H (2004) Protection of androgendependent human prostate cancer cells from oxidative stress-induced DNA damage by overexpression of clusterin and its modulation by androgen. Prostate 61: 318-323

Miyake H, Hara I, Kamidono S, Gleave ME (2001a) Synergistic chemsensitization and inhibition of tumor growth and metastasis by the antisense oligodeoxynucleotide targeting clusterin gene in a human bladder cancer model. Clin Cancer Res 7: 4245-4252

Miyake H, Hara S, Arakawa S, Kamidono S, Hara I (2002) Over expression of clusterin is an independent prognostic factor for nonpapillary renal cell carcinoma. J Urol 167: 703-706

Miyake H, Hara S, Zellweger T, Kamidono S, Gleave ME, Hara I (2001b) Acquisition of resistance to Fas-mediated apoptosis by overexpression of clusterin in human renal-cell carcinoma cells. Mol Urol 5: 105-111

Miyake H, Kurahashi T, Takenaka A, Inoue TA, Fujisawa M (2009) Clinical outcome of combined immunotherapy with interferon-alpha and lowdose interleukine-2 for Japanese patients with metastatic renal cell carcinoma. Urol Oncol 27: 598-603

Miyake H, Monia BP, Gleave ME (2000a) Inhibition of progression to androgen-independence by combined adjuvant treatment with antisense BCL-XL and antisense Bcl-2 oligonucleotides plus taxol after castration in the Shionogi tumor model. Int J Cancer 86: 855-862

Miyake H, Nelson C, Rennie PS, Gleave ME (2000b) Testosterone-repressed prostate message- 2 is an antiapoptotic gene involved in progression to androgen independence in prostate cancer. Cancer Res 60: 170-176

Miyake H, Nelson C, Rennie PS, Gleave ME (2000c) Acquisition of chemoresistant phenotype by overexpression of the antiapoptotic gene testosterone-repressed prostate message- 2 in prostate cancer xenograft models. Cancer Res 60: 2547-2554

Miyake H, Pollak M, Gleave ME (2000d) Castration-induced up-regulation of insulin-like growth factor binding protein-5 potentiates insulin-like growth factor-I activity and accelerates progression to androgen independence in prostate cancer models. Cancer Res 60: 3058-3064

Miyake H, Tolcher A, Gleave ME (1999) Antisense Bcl-2 oligodeoxynucleotides inhibit progression to androgen-independence after castration in the Shionogi tumor model. Cancer Res 59: 4030-4040

Miyake H, Yamanaka K, Muramaki M, Hara I, Gleave ME (2005) Therapeutic efficacy of adenoviral-mediated p53 gene transfer is synergistically enhanced by combined use of antisense oligodeoxynucleotide targeting clusterin gene in a human bladder cancer model. Neoplasia 7: 171-179

Parton M, Gore M, Eisen T (2006) Role of cytokine therapy in 2006 and beyond for metastatic renal cell cancer. J Clin Oncol 24: 5584-5592

Rini BI, Rathmell WK, Godley P (2008) Renal cell carcinoma. Curr Opin Oncol 20: 300-306

Rocchi P, Beraldi E, Ettinger S, Fazli L, Vessella RL, Nelson C, Gleave M (2005) Increased Hsp27 after androgen ablation facilitates androgenindependent progression in prostate cancer via signal transducers and activators of transcription 3-mediated suppression of apoptosis. Cancer Res 65: 11083-11093

Shannan B, Seifert M, Leskov K, Willis J, Boothman D, Tilgen W, Reichrath J (2006) Challenge and promise: roles for clusterin in pathogenesis, progression and therapy of cancer. Cell Death Differ 13: 12-19 
So A, Hadaschik B, Sowery R, Gleave M (2007) The role of stress proteins in prostate cancer. Curr Genomics 8: 252-261

Stadler WM, Figlin RA, McDermott DF, Dutcher JP, Knox JJ, Miller Jr WH, Hainsworth JD, Henderson CA, George JR, Hajdenberg J, KindwallKeller TL, Ernstoff MS, Drabkin HA, Curti BD, Chu L, Ryan CW, Hotte SJ, Xia C, Cupit L, Bukowski RM (2010) Safety and efficacy results of the advanced renal cell carcinoma sorafenib expanded access program in North America. Cancer 116: 1272-1280

Wilhelm S, Carter C, Lynch M, Lowinger T, Dumas J, Smith RA, Schwartz B, Simantov R, Kelley S (2006) Discovery and development of sorafenib: a multikinase inhibitor for treating cancer. Nat Rev Drug Discov 5: 835-844

Wilhelm SM, Adnane L, Newell P, Villanueva A, Llovet JM, Lynch M (2008) Preclinical overview of sorafenib, a multikinase inhibitor that targets both Raf and VEGF and PDGF receptor tyrosine kinase signaling. Mol Cancer Ther 7: 3129-3140

Yamanaka K, Rocchi P, Miyake H, Fazli L, Vessella B, Zangemeister-Wittke U, Gleave ME (2005) A novel antisense oligonucleotide inhibiting several antiapoptotic Bcl-2 family members induces apoptosis and enhances chemosensitivity in androgen-independent human prostate cancer PC3 cells. Mol Cancer Ther 4: 1689-1698
Zellweger T, Chi K, Miyake H, Adomat H, Kiyama S, Skov K, Gleave ME (2002) Enhanced radiation sensitivity in prostate cancer by inhibition of the cell survival protein clusterin. Clin Cancer Res 8: 3276-3284

Zellweger T, Miyake H, July LV, Akbari M, Kiyama S, Gleave ME (2001) Chemosensitization of human renal cell cancer using antisense oligonucleotides targeting the antiapoptotic gene clusterin. Neoplasia 3: 360-367

Zhang H, Kim JK, Edwards CA, Xu Z, Taichman R, Wang CY (2005) Clusterin inhibits apoptosis by interacting with activated Bax. Nat Cell Biol 7: 909-915

Zhong B, Sallman DA, Gilvary DL, Pernazza D, Sahakian E, Fritz D, Cheng JQ, Trougakos I, Wei S, Djeu JY (2010) Induction of clusterin by AKT-role in cytoprotection against docetaxel in prostate tumor cells. Mol Cancer Ther 9: 1831-1841

Zoubeidi A, Chi K, Gleave M (2010a) Targeting the cytoprotective chaperone, clusterin, for treatment of advanced cancer. Clin Cancer Res 16: 1088-1093

Zoubeidi A, Ettinger S, Beraldi E, Hadaschik B, Zardan A, Klomp LW, Nelson CC, Rennie PS, Gleave ME (2010b) Clusterin facilitates COMMD1 and I- $\kappa \mathrm{B}$ degradation to enhance NF- $\kappa \mathrm{B}$ activity in prostate cancer cells. Mol Cancer Res 8: 119-130

This work is published under the standard license to publish agreement. After 12 months the work will become freely available and the license terms will switch to a Creative Commons Attribution-NonCommercial-Share Alike 3.0 Unported License. 